\title{
Optimization of the solvent-exchange process for high-yield synthesis of aqueous fullerene dispersions
}

\author{
I. V. Mikheev ${ }^{1,2}$, M. O. Pirogova ${ }^{1}$, T. A. Bolotnik ${ }^{1,2}$, D. S. Volkov ${ }^{1,2}$, M. V. Korobov ${ }^{1}$, M. A. Proskurnin ${ }^{1,2}$ \\ ${ }^{1}$ Chemistry Department, Lomonosov Moscow State University, Moscow, Russia \\ ${ }^{2}$ Analytical Centre of Lomonosov Moscow State University / Agilent Technologies Authorized Partner \\ Laboratory, Moscow, Russia \\ mikheev.ivan@gmail.com,mariy7991@yandex.ru,timab@tut.by,dmsvolkov@gmail.com, \\ mkorobov49@gmail.com, proskurnin@gmail.com
}

PACS 68.55.ap, 81.05.ub

DOI 10.17586/2220-8054-2018-9-1-41-45

\begin{abstract}
The ultrasound-assisted solvent-exchange technique for aqueous fullerene dispersions (AFD) of $\mathrm{C}_{60}\left(10^{-4}-10^{-6} \mathrm{M}\right)$ have been improved for high-yield synthesis, thereby achieving AFDs with total recovery over $90 \%$. Using ICP-AES, HPLC-UV, HGC-MS, the elemental and residual organic compounds have been estimated as not exceeding $3 \mathrm{ppm}$. The possible structure of fullerene clusters in AFD was assumed as $\left\{n\left[\mathrm{C}_{60}\right] m \mathrm{C}_{6} \mathrm{H}_{5} \mathrm{COO}^{-}(m-x) \mathrm{Na}^{+}\right\} x \mathrm{Na}^{+}$.
\end{abstract}

Keywords: solvent-exchange process, fullerene $\mathrm{C}_{60}$, stability, atomic spectroscopy.

Received: 16 June 2017

Revised: 1 September 2017

\section{Introduction}

Fullerene-based materials have already been used in new composite materials with superconducting properties, photoresist masks, lubricants, etc. [1-8]. Fullerenes find the application in medicine and cosmetology, as well as in such areas as theranostics, nanomedicine, drug delivery, etc. Among the most promising are aqueous fullerene dispersions (AFDs), with a wide range of applications in medicine and other fields that require fullerenes in aqueous media [9-13]. AFDs of unmodified fullerenes are preferable due to biocompatibility and safety: owing to their open surface without moieties, they are not involved in metabolic processes. This is especially the case of endohedral metallofullerene (EMF) AFDs, which are promising contrast agents.

Expanding the range of AFD applications requires improvement in their preparation. Derivatization and solubilization have been disregarded in this field. The most relevant techniques of AFD preparation are solvent exchange [11,14,15], dialysis [16], and mixing [17-19]. However, the total yield of fullerene transfer into water of $100 \%$ has not yet been achieved, which leads to significant losses and increases for the cost of the final product, especially for EMFs. The ultrasound-assisted solvent-exchange procedure produces AFDs from a range of neat solvents, both polar and nonpolar, and that are stable for long periods. There was no previously described exact mechanism for the solubilization, although some research has dealt with the prediction of dispersion stability.

Apart from the yield, the main drawback for the solvent-exchange process is significant amounts of hazardous organic substances in AFDs $[11,14,15]$. However, not much attention is paid to the purity of the produced dispersions, which is unacceptable for biomedicine. Therefore, it is necessary to develop techniques for purification and determination of the residual amounts of organic substances. Here, the ultrasound-assisted solvent-exchange procedure has been optimized for preparing AFD with a yield close to $100 \%$. We selected widely available fullerene $\mathrm{C}_{60}$ and toluene due to its lower volatility compared to benzene and good solubility of $\mathrm{C}_{60}$.

\section{Materials and methods}

To produce AFD and improve reagent dissolution during the preparation, a GRAD 180-35 (LLC GradTechnology, Russia) ultrasonic bath was used. Weighing was performed on an Ohaus DV-114C analytical balance (Switzerland). Absorbance measurements in the UV/vis range were carried out using an Agilent Cary 4000 (Australia). Pure toluene Reakhim (Russia), ultra-pure water "type 1" from a Milli-Q Millipore Corporation water purification system, $18.2 \mathrm{~m} \Omega \times \mathrm{cm}$, pure potassium hydrogen phthalate "Merck" (Germany), fullerene C 60 99.5 \% LLC NeoTechProdukt (Russia) were used. Elemental analysis was performed by an Agilent ICP-AES 720 (Malaysia) with ICP Expert software 2.0.5 according to ISO 11885:2007(en). All emission lines (Table 1) were measured simultaneously (a MultiCal mode). To estimate volatile organic compounds, Headspace Gas Chromatography Mass Spectrometry (HGC-MS) Shimadzu, Germany was used. A CP Sil 5 CB column $(25 \mathrm{~m} \times 0.25 \mathrm{~mm} \times 0.4 \mu \mathrm{M}$, 
starting temperature $40{ }^{\circ} \mathrm{C}$, isotherm for $5 \mathrm{~min}$, temperature increase up to $130{ }^{\circ} \mathrm{C}$, temperature pitch $9{ }^{\circ} \mathrm{C} / \mathrm{min}$, isotherm for $3 \mathrm{~min}$ ). For benzoate detection in AFDs, Agilent $1200 \mathrm{HPLC}-\mathrm{UV}$ was used with an Eclipse XDBC18 column (Agilent, USA) $150 \times 4.6 \mathrm{~mm}$, sorbent particle diameter, $5 \mu \mathrm{m}$; precolumn Security Guard C18 $\left(4 \times 3 \mathrm{~mm}\right.$; Phenomenex, USA); column temperature: $35^{\circ} \mathrm{C}$; sample volume: $100 \mu \mathrm{L}$; mobile phase: Eluent A, $0.2 \%$ phosphoric acid $(83 \% \mathrm{v} / \mathrm{v})$, Eluent B, acetonitrile $(17 \% \mathrm{v} / \mathrm{v})$; mobile phase rate: $1 \mathrm{~mL} / \mathrm{min}$; detection conditions: wavelength $235 \mathrm{~nm}$, spectral bandwidth $4 \mathrm{~nm}$. LOD and LOQ were calculated according to IUPAC 1998 recommendations.

TABLE 1. ICP-AES measurements conditions

\begin{tabular}{cc}
\hline \hline \multicolumn{2}{c}{ Instrumental conditions settings } \\
\hline RF power (kW) & 1.40 \\
\hline Plasma flow (L/min) & 15 \\
\hline Axial flow (L/min) & 1.50 \\
\hline Nebulizer flow (L/min) & 0.70 \\
\hline Replicate read time (s) & 5 \\
\hline Plasma stabilization delay (s) & 15 \\
\hline \multicolumn{3}{c}{ Replicates } & 3 \\
\hline Sample introduction settings \\
\hline Sample uptake delay (s) & 15 \\
\hline \multicolumn{2}{c}{ Pump rate (rpm) }
\end{tabular}

\section{Results and discussion}

Aqueous fullerene $\mathrm{C}_{60}$ dispersions were obtained by the ultrasound-assisted solvent exchange process that is generally known in colloidal chemistry. This approach was previously applied for AFDs [11,12,20]. Nevertheless, here, we have applied and developed methods and approaches to improve the yield and physicochemical properties, as well as the sample purity. We have previously published [1-4] the data concerning fullerene state in pristine fullerene samples before ultrasound treatment and as well fullerene ultrasound-assisted solvent-exchange process. We have not observed any peaks with masses higher than the molecular ion peak $[\mathrm{M}]^{+\cdot}($ e.g. epoxy-, hydroxyl-, derivatives, and polymeric structures: dimeric, trimeric, etc.) for both pristine fullerene and their aqueous dispersions).

\subsection{Quantitative determination of fullerenes}

For the quantification of fullerenes both in the aqueous and in the organic phases, UV/vis spectroscopy was used. For toluene, the absorption spectra and the apparent molar absorptivity $\left(\varepsilon_{407}=3.5 \pm 0.2 \mathrm{M}^{-1} \mathrm{~cm}^{-1}\right) \mathrm{coincide}$ with the existing data [17,21,22]. For the quantification, a wavelength of $407 \mathrm{~nm}$ was used. LOD and LOQ for $\mathrm{C}_{60}$ fullerene in toluene are 100 and $400 \mathrm{nM}$. These values are acceptable for the optimization of solvent-exchange procedures for a wide range of concentrations up to micromolar. Quantification of fullerenes in the aqueous phase requires a strict control of carbon species. A drawback of solvent-exchange procedures is residual organic solvents, which result in overestimation of fullerenes by a TOC analyzer. By purging for $16 \mathrm{~h}$, we reduced up to $44 \%$ the total quantity of the volatile organic matter (Fig. 1 and Fig. 2). The initial content of toluene in AFD is $0.044 \pm 0.005 \mathrm{ppm}$ (Fig. 1) and about 25 hours are necessary to reduce its content to ppb level or less. To the best of our knowledge, it is the first description of purging for purification of AFDs $\mathrm{C}_{60}$ from nonpolar organic admixtures. This approach is cheaper and no less effective compared to solid-phase extraction (using C18-sorbents).

After checking the aqueous dispersions, a combination of TOC and UV/vis. measurements allowed us to calculate an apparent molar absorptivity (Table 2) $[9,11]$. These data have a good correlation with existing data that we used for fullerene quantification. LOD and LOQ were 100 and $300 \mathrm{nM}$, respectively (at $349 \mathrm{~nm}$ ). Thus, due to the selected conditions with coincided performance parameters for fullerene $\mathrm{C}_{60}$ in toluene and in their AFD, we can proceed to the adjusting of optimal conditions for obtaining AFD in high-yield synthesis. 


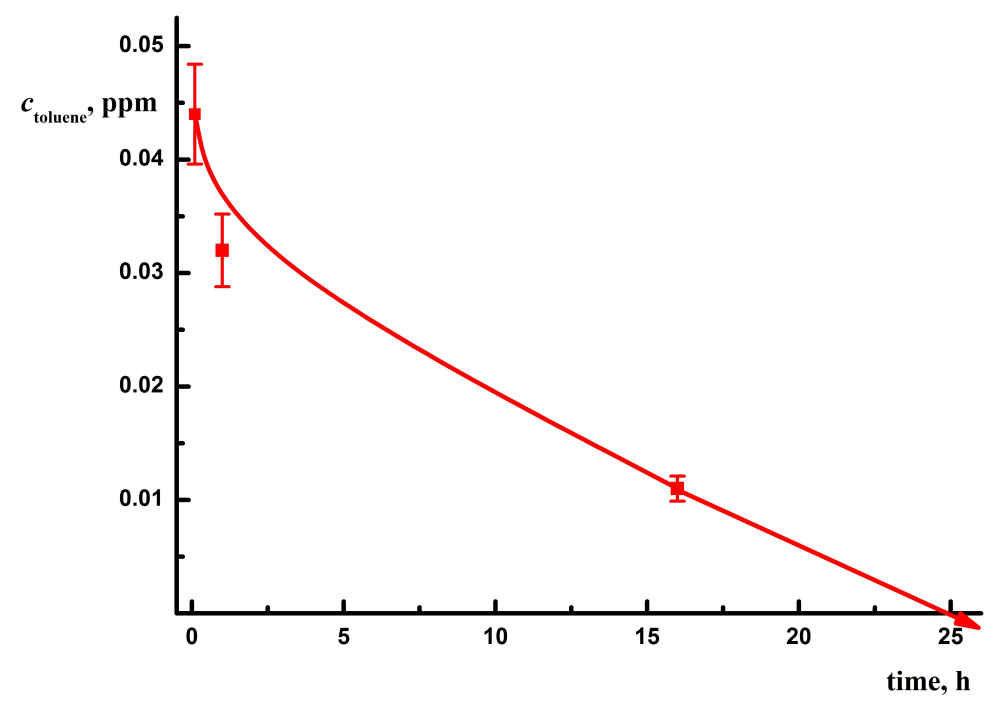

FIG. 1. Dependence of toluene concentration in AFD on the argon purging time (rate, $100 \mathrm{~mL} / \mathrm{min}$ ) by HGC-MS

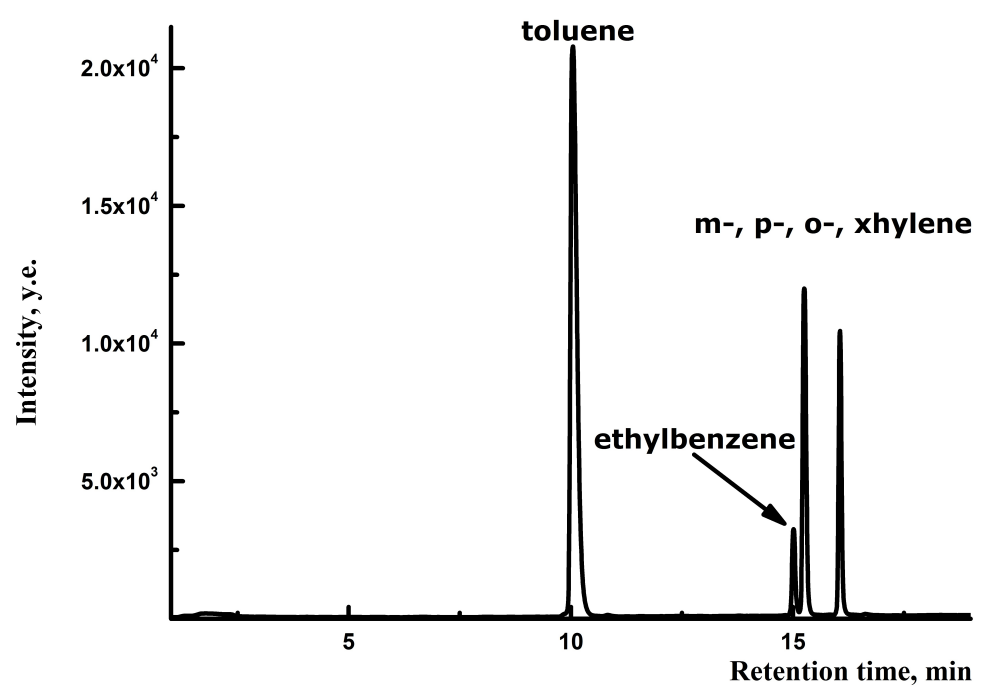

FIG. 2. Representative HS GC-MS chromatograms are registered on $91 \mathrm{Da} \mathrm{m} / \mathrm{z}$ for non-purging AFD $\mathrm{C}_{60}$

TABLE 2. Apparent molar absorptivities for $\mathrm{C}_{60}$ in water and its deviation from existing data

\begin{tabular}{cccc}
\hline$\lambda, \mathrm{nm}$ & $\varepsilon \times 10^{3} \mathrm{M}^{-1} \mathrm{~cm}^{-1}$ & $\varepsilon \times 10^{3} \mathrm{M}^{-1} \mathrm{~cm}^{-1}[9,11]$ & $\delta \varepsilon, \%$ \\
\hline 349 & $49 \pm 1$ & $49 \pm 2$ & 0.7 \\
\hline 268 & $71 \pm 8$ & $67 \pm 6$ & 5.6 \\
\hline 220 & $69 \pm 8$ & $60 \pm 6$ & 13.0 \\
\hline
\end{tabular}

\subsection{Optimization of the solvent-exchange process for fullerene $\mathbf{C}_{60}$ AFD from toluene}

Having calculated the LOD and LOQ for fullerene $\mathrm{C}_{60}$ in toluene and in AFD, we improved the conditions for obtaining AFD using ultrasound baths with higher electric power (up to $1 \mathrm{~kW}$ ) and Erlenmeyer flasks with the lowest glass thickness (down to $3 \mathrm{~mm}$ ). The main optimization point consisted of using different ratios of fullerene in toluene and water. It was found that the appropriate recovery values (more $50 \%$ ) was achieved for the fullerene 
concentration in toluene in the range of $n \times 10^{-5} \mathrm{M}$. The concentration range from $n \times 10^{-6} \mathrm{M}$ to $n \times 10^{-4} \mathrm{M}$ was tested.

At different ratios of $\mathrm{C}_{60}$ in toluene to water, the total volume of the toluene-water system did not differ by more than $15 \%$ by volume. Thus, we could use the same Erlenmeyer flasks for $250 \mathrm{~mL}$ to obtain more reproducible results. The average time of ultrasonic treatment was about $12 \mathrm{~h}$ at an electric power of $0.9 \mathrm{~kW}$.

Hydrophobic fullerene nanoparticles in AFDs show a negative zeta-potential in water. In all cases, we found values $<-20 \mathrm{mV}$. Polydispersity indexes for all solutions were $0.10-0.15$. These values are close to those for a material with a unimodal distribution of nanoparticles. The optimum conditions provide the transfer of fullerene up to $100 \%$ into aqueous media for $\mathrm{C}_{60}$. ICP-AES was used for determining elemental composition for major components of the glass vessel (sodium, silicon, calcium etc.) in the final solution; the total concentration of elements is 3 ppm (Table 3 ).

TABLE 3. The recovery of fullerenes in two parallel experiments, the average recovery value, $(n=2, P=0.95)$ and the results of elemental analysis using the ICP-AES $(n=3, P=0.95)$

\begin{tabular}{cccccc}
\hline $\begin{array}{c}\mathrm{C}_{60} \\
\begin{array}{c}\text { toluene/water } \\
\text { ratio }\end{array}\end{array}$ & $\begin{array}{c}\text { Recovery (I) } \mathrm{C}_{60} \\
\text { into aqueous } \\
\text { phase, } \%\end{array}$ & $\begin{array}{c}\text { Recovery (II) } \mathrm{C}_{60} \\
\text { into aqueous } \\
\text { phase, } \%\end{array}$ & $\begin{array}{c}\text { Average recovery } \\
\text { (I) } \mathrm{C}_{60} \text { into aqueous } \\
\text { phase, } \%\end{array}$ & $\begin{array}{c}\text { Sodium, } \\
\text { ppb }^{1}\end{array}$ & $\begin{array}{c}\text { Silicon, } \\
\text { ppb }^{1}\end{array}$ \\
\hline $2: 1$ & $29 \pm 5$ & $22 \pm 3$ & $26 \pm 8$ & $160 \pm 24$ & $102 \pm 15$ \\
\hline $1: 2$ & $34 \pm 5$ & $26 \pm 6$ & $30 \pm 11$ & $580 \pm 87$ & $2081 \pm 312$ \\
\hline $1: 1$ & $55 \pm 2$ & $49 \pm 4$ & $52 \pm 6$ & $199 \pm 30$ & $280 \pm 42$ \\
\hline $1: 5$ & $91 \pm 5$ & $93 \pm 5$ & $92 \pm 10$ & $211 \pm 32$ & $550 \pm 83$ \\
\hline $1: 10$ & $6 \pm 2$ & $3 \pm 1$ & $4 \pm 3$ & $266 \pm 40$ & $319 \pm 48$ \\
\hline $1: 25$ & $1.5 \pm 0.2$ & $1.7 \pm 0.3$ & $1.6 \pm 0.5$ & $35 \pm 5$ & $36 \pm 5$ \\
\hline
\end{tabular}

${ }^{1}$ Another elements concentration: Ag, Al, As, Ba, Be, Cd, Co, Cr, Fe, K, Li, Mn, Mo, Ni, Pb, Sb, Sn, Sr, Ti, Tl, V, W, Zr $<1 \mathrm{ppb}, \mathrm{Cu}<3 \mathrm{ppb}, \mathrm{K}, \mathrm{Mg}, \mathrm{Ca}<80 \mathrm{ppb}, \mathrm{B}<100 \mathrm{ppb}$

HPLC-UV showed that the total value of benzoate (a product of ultrasound oxidation of toluene) was no more $30 \mathrm{ppb}$. We assumed the possible clustered structure of the micelle which including $\left\{n\left[\mathrm{C}_{60}\right] m \mathrm{C}_{6} \mathrm{H}_{5} \mathrm{COO}^{-}(m-x) \mathrm{Na}^{+}\right\} x \mathrm{Na}^{+}$, which can provide, apparently, the most probable source of stabilization of fullerenes. It has no impact on increasing ionic strength and AFD stability. In certain conditions, there is a complete shift of the equilibrium in a one-component system towards AFD formation.

\section{Conclusions}

The conditions for high-yield preparation of all types of AFDs have been found. Our results highlighted optimization techniques for obtaining stable aqueous dispersions. Obviously, in the future, this technique should be employed for higher-order fullerenes and metallofullerenes. A special role in this, of course, will be played by metal-containing fullerenes. First, since the cost of the initial samples is now very high. Secondly, in view of the unique structure and their paramagnetic properties $\left(e . g . \mathrm{Gd}^{3+}\right)$ of aqueous dispersions, there are promising applications for studying and using them as contrast agents in MRI. Additionally, such work will provide a means to approach solutions for difficult problems, such as establish the nature of the fullerenes' stability in their AFDs.

\section{Acknowledgements}

The work is supported by The Russian Science Foundation, grant no. 14-23-00012-P. We are grateful to Agilent Technologies - Russia and its CEO, Dr. Konstantin Evdokimov, for the equipment used in this study.

\section{References}

[1] Dresselhaus S., Dresselhaus G., Eklund P.C. Science of Fullerenes and Carbon Nanotubes: Their Properties and Applications. Elsevier Science, 1996.

[2] Thakur V.K., Thakur M.K. Chemical Functionalization of Carbon Nanomaterials: Chemistry and Applications. CRC Press, 2015.

[3] Yang S., Wang C.R. Endohedral Fullerenes: From Fundamentals to Applications. World Scientific Publishing Company, 2014.

[4] Karas M., Bahr U., et al. Principles and applications of matrix-assisted UV-laser desorption/ionization mass spectrometry. Analytica Chimica Acta, 1990, 241 (2), P. 175-185. 
[5] Jensen A.W., Wilson S.R., Schuster D.I. Biological applications of fullerenes. Bioorganic \& Medicinal Chemistry, 1996, 4(6), P. 767-779.

[6] Georgakilas V., Perman J.A., Tucek J., Zboril R. Broad Family of Carbon Nanoallotropes: Classification, Chemistry, and Applications of Fullerenes, Carbon Dots, Nanotubes, Graphene, Nanodiamonds, and Combined Superstructures. Chem. Rev., 2015 , 115 (11), P. 4744-4822.

[7] Anilkumar P., Lu F., et al. Fullerenes for applications in biology and medicine. Curr. Med. Chem., 2011,18 (14), P. 2045-2059.

[8] Bakry R., Vallant R.M., et al. Medicinal applications of fullerenes. Intern. J. Nanomedicine, 2007,2 (4), P. 639-649.

[9] Andrievsky G.V., Klochkov V.K., Bordyuh A.B., Dovbeshko G.I. Comparative analysis of two aqueous-colloidal solutions of C60 fullerene with help of FTIR reflectance and UVVis spectroscopy. Chem. Phys. Lett., 2002, 364 (1-2), P. 8-17.

[10] Mchedlov-Petrossyan N.O., Klochkov V.K., Andrievsky G.V. Colloidal dispersions of fullerene $\mathrm{C}_{60}$ in water: some properties and regularities of coagulation by electrolytes. J. Chem. Soc., Faraday Trans., 1997, 93 (24), P. 4343-4346.

[11] Mikheev I.V., Khimich E.S., et al. Quasi-equilibrium distribution of pristine fullerenes $\mathrm{C}_{60}$ and $\mathrm{C}_{70}$ in a watertoluene system. Carbon, 2017, 111, P. 191-197.

[12] Mikheev I.V., Volkov D.S., Proskurnin M.A., Korobov M.V. Monitoring of Aqueous Fullerene Dispersions by Thermal-Lens Spectrometry. Intern. J. Thermophysics, 2015, 36 (5-6), P. 956-966.

[13] Kyzyma E.A., Tomchuk A.A., et al. Structure and toxicity of aqueous fullerene $\mathrm{C}_{60}$ solutions. J. Surf. Investigation. X-ray, Synchrotron and Neutron Techniques, 2015, 9 (1), P. 1-5.

[14] Hilburn M.E., Murdianti B.S., et al. Synthesizing aqueous fullerene colloidal suspensions by new solvent-exchange methods. Colloids and Surfaces A: Physicochem. Engin. Aspects, 2012, 401, P. 48-53.

[15] Maples R.D., Hilburn M.E., et al. Optimized solvent-exchange synthesis method for C60 colloidal dispersions. J. Colloid Interface Sci., 2012, 370 (1), P. 27-31.

[16] Andreev S.M., Purgina D.D., et al. Facile preparation of aqueous fullerene $\mathrm{C}_{60}$ nanodispersions. Nanotechnologies in Russia, 2014, 9 (7), P. 369-379.

[17] Chang X., Vikesland P.J. UVvis Spectroscopic Properties of $\mathrm{nC}_{60}$ Produced via Extended Mixing. Environmental Sci. \& Technol., 2011, 45 (23), P. 9967-9974.

[18] Brant J.A., Labille J., Bottero J.-Y., Wiesner M.R. Characterizing the Impact of Preparation Method on Fullerene Cluster Structure and Chemistry. Langmuir, 2006, 22 (8), P. 3878-3885.

[19] Zhang W., Rattanaudompol U.s., Li H., Bouchard D. Effects of humic and fulvic acids on aggregation of aqu/nC 60 nanoparticles. Water Research, 2013, 47 (5), P. 1793-1802.

[20] Mikheev I.V., Usoltseva L.O., et al. Approach to the Assessment of Size-Dependent Thermal Properties of Disperse Solutions: TimeResolved Photothermal Lensing of Aqueous Pristine Fullerenes $\mathrm{C}_{60}$ and $\mathrm{C}_{70}$. J. Phys. Chem. C, 2016,120 (49), P. $28270-28287$.

[21] Hare J.P., Kroto H.W., Taylor R. Preparation and UV / visible spectra of fullerenes $\mathrm{C}_{60}$ and C 70. Chem. Phys. Lett., 1991, 177 (4-5), P. 394-398.

[22] Bensasson R.V., Bienvenue E., et al. $\mathrm{C}_{60}$ in Model Biological Systems. A Visible-UV Absorption Study of Solvent-Dependent Parameters and Solute Aggregation. J. Phys. Chem., 1994, 98 (13), P. 3492-3500. 